\title{
Helicobacter pylori infection, serum pepsinogens as markers of atrophic gastritis, and leukocyte telomere length: a population-based study
}

Khitam Muhsen ${ }^{1 *}$ D, Ronit Sinnreich ${ }^{2}$, Dafna Merom ${ }^{3}$, Hisham Nassar $^{4}$, Dani Cohen ${ }^{1 \dagger}$ and Jeremy D. Kark ${ }^{2+\wedge}$

\begin{abstract}
Background: Persistent infections that induce prolonged inflammation might negatively affect the leukocyte telomere length (LTL); however, the role in LTL of Helicobacter pylori (H. pylori) infection, which persistently colonizes the stomach, remains unknown.

The study objective was to examine associations of sero-prevalence of $H$. pylori immunoglobulin $\mathrm{G}(\mathrm{lgG})$ antibody and serum pepsinogens (PGs), as markers of atrophic gastritis, with LTL.

A cross-sectional study was performed among 934 Arab residents of East Jerusalem, aged 27-78 years, randomly selected from Israel's national population registry. Sera were tested for H. pylori lgG and PG levels by ELISA. LTL was measured by southern blots. Multiple linear regression models were fitted to adjust for sociodemographic and lifestyle factors.
\end{abstract}

Results: LTL decreased significantly with age $(p<0.001)$ and was shorter in men than women $(p=0.032)$. The mean LTL was longer in $\mathrm{H}$. pylori sero-positive persons than negative ones: mean difference $0.13 \mathrm{~kb}(95 \% \mathrm{Cl} 0.02,0.24), p=0.016$. Participants with atrophic gastritis $(P G l<30 \mu \mathrm{g} / \mathrm{L}$ or a PGl: PGIl < 3.0) had shorter LTL than did those without: mean difference $-0.18(95 \% \mathrm{Cl}-0.32,-0.04)$. The difference was of larger magnitude between persons who had past $H$. pylori infection (sero-negative to H. pylori lgG antibody) and atrophic gastritis, compared to those who were H. pylori seronegative and did not have atrophic gastritis: mean difference $-0.32 \mathrm{~kb}(95 \% \mathrm{Cl}-0.55,-0.10)$. This association remained significant after adjustment for age, sex, and religiosity: beta coefficient $-0.21 \mathrm{~kb}(95 \% \mathrm{Cl}-0.41,-0.001), p=0.049$. The results were similar after further adjustment for lifestyle factors. In bivariate analysis, mean LTL was longer in physically active persons than non-active ones, and shorter in persons with than without obesity; however, these differences were diminished and were not significant in the multivariable model.

Conclusions: H. pylori lgG sero-positivity per se was not related to reduced LTL. However, persons with past H. pylori infection (i.e., lacking H. pylori lgG serum antibody) and with serological evidence of atrophic gastritis, had a significantly shorter LTL than did those without atrophic gastritis.

Keywords: Leukocyte telomere length, Helicobacter pylori, Serum pepsinogens, Atrophic gastritis, Cytotoxin-associated gene $A$ antigen

\footnotetext{
* Correspondence: kmuhsen@tauex.tau.ac.il

${ }^{\dagger}$ Dani Cohen and Jeremy D. Kark had equal contribution as senior authors.

Deceased

${ }^{1}$ Department of Epidemiology and Preventive Medicine, School of Public Health, Sackler Faculty of Medicine, Tel Aviv University Ramat Aviv, Ramat Aviv, 6139001 Tel Aviv, Israel

Full list of author information is available at the end of the article
}

(c) The Author(s). 2019 Open Access This article is distributed under the terms of the Creative Commons Attribution 4.0 International License (http://creativecommons.org/licenses/by/4.0/), which permits unrestricted use, distribution, and reproduction in any medium, provided you give appropriate credit to the original author(s) and the source, provide a link to the Creative Commons license, and indicate if changes were made. The Creative Commons Public Domain Dedication waiver (http://creativecommons.org/publicdomain/zero/1.0/) applies to the data made available in this article, unless otherwise stated. 


\section{Background}

Telomeres are repetitive nucleotides at the ends of eukaryotic chromosomes $[1,2]$ that are essential for genomic stability. Telomere length shortens with every cell division, due to the inability of DNA polymerase to extend DNA ends [1, 3]. Telomeres that shorten beyond a critical level cause cellular senescence [1, 3]; thus, telomere length has a considerable impact on human health [4].

Leukocyte telomere length (LTL) is commonly assessed in epidemiological studies [4]. LTL is affected by heredity $[5,6]$; decreases with age $[5,7,8]$; is longer in females than males $[7,8]$; correlates positively with paternal age at conception [6]; and varies by race, being longer, for example, in persons of African ancestry than individuals of European ancestry [4, 7, 9].

Shorter LTL was consistently linked to increased risk of atherosclerosis [10-15] and reduced survival [16-18]. The association between LTL and cancer risk is less consistent [19]. Some studies showed an increased risk for cancer in relation to short LTL $[20,21]$, while in other studies longer LTL was associated with increased cancer risk [22]. Given the importance of telomere length in human health, searching for modifiable determinants of LTL is highly desirable. Persons of low socioeconomic status displayed shorter LTL than did persons of high socioeconomic status [23]. Smokers were found to have shorter LTL than never or former smokers [24, 25]. Obesity [25] and higher body mass index (BMI) [26] were associated with shorter telomeres [26], while a positive association was found of physical activity with telomere length [27, 28]. An inverse association was shown between dietary caloric intake and LTL in men [29]. Persistent infections have been suggested to play a role in telomere length through the induction of oxidative stress and inflammation [30, 31]. For example, associations were reported of exposure to cytomegalovirus (CMV), herpes simplex virus type 1 (HSV-1), and human herpes virus 6 with greater LTL attrition in healthy adults [31], although these associations were not affected by systemic non-specific inflammatory markers such as C-reactive protein and interleukin 6 [31]. If infectious agents are truly associated with LTL, associations would be expected between tissue damage induced by these pathogens and LTL. Helicobacter pylori (H. pylori), a gram-negative bacterium that colonizes the stomach, can serve as a model to examine this hypothesis. $H$. pylori infection is acquired in childhood [32]. While $H$. pylori cause chronic gastritis in almost all infected persons, some present with peptic ulcers and gastric cancer in adulthood, especially those infected with strains that express cytotoxin-associated gene A (CagA) virulence antigen (reviewed in [33, 34]). Pepsinogen I (PGI) and PGII, pro-enzymes of pepsin, are secreted into the gastric lumen, and small amounts can be found in the serum $[35,36]$. With increasing severity of $H$. pylori gastritis, serum PGI and PGII levels increase, but when atrophic gastritis ensues, the PGI level and the PGI:PGII ratio decrease. Serum PGs can predict atrophic gastritis and gastric cancer [37-41]. The objective of the current study was to examine associations of the sero-prevalence of $H$. pylori immunoglobulin G (IgG) antibody and serological evidence of atrophic gastritis with LTL in a general population sample.

\section{Results}

\section{Description of the study sample}

Overall, 934 participants $(53.1 \%$ men) were tested for both $H$. pylori IgG antibody and LTL. The age at examination ranged from 27.0 to 78.0 years, with a mean of 52.0 years (standard deviation [SD] 13.9), which was similar among men and women. Most (64.2\%) participants had not completed high school; this was more true for women $(70.3 \%)$ than men $(58.8 \%)$. Most participants (62.4\%) defined themselves as traditional/secular: $67.5 \%$ and $56.6 \%$ in men and women, respectively. Overall, $82.0 \%$ of the participants reported being married; $94.2 \%$ and $68.1 \%$ among men and women, respectively. The overall prevalence of smoking was $26.0 \%: 40.8 \%$ in men and $9.0 \%$ in women; the respective figures for obesity were $44.1 \%, 31.9 \%$, and $58.0 \%$ (Table 1 ).

\section{Mean LTL according to demographic and lifestyle factors}

The LTL values ranged from $4.72 \mathrm{~kb}$ to $8.53 \mathrm{~kb}$, with a mean of $6.76 \mathrm{~kb}$ (SD 0.61). The mean LTL was longer in women than men $(p=0.073)$. The mean LTL was longest in the youngest age group (27-34 years), $7.18 \mathrm{~kb}$ (SD $0.55)$, and decreased progressively in older age groups, reaching $6.40 \mathrm{~kb}(\mathrm{SD} 0.55)$ at age $65-78$ years $(p<0.001)$. All pairwise comparisons between the age groups were statistically significant by the Bonferroni test. The mean LTL differed significantly ( $p=0.007)$ according to education, with a mean $6.72 \mathrm{~kb}$ (SD 0.58) among participants who had not completed high school, $6.83 \mathrm{~kb}$ (SD 0.61) in those who had completed high school ( $p=0.055$ by the Bonferroni test), and $6.87 \mathrm{~kb}$ (SD 0.71) in participants with academic education ( $p=0.033$ by the Bonferroni test). Persons who defined themselves as religious had shorter mean LTL than persons who defined themselves as traditional or secular $(p<0.001)$. Married individuals had longer mean LTL than unmarried ones: mean difference 0.11 (95\% confidence intervals [CI] 0.01, 0.21), $p=0.039$. Persons with obesity had shorter mean LTL, $6.71 \mathrm{~kb}$ (SD 0.60), than persons without obesity, $6.80 \mathrm{~kb}$ (SD 0.62), $(p=0.025)$. Physically active persons had longer mean LTL than non-active ones $(p<0.001)$; this association was found both for physical activity that 
Table 1 Characteristics of the study sample

\begin{tabular}{|c|c|c|c|}
\hline & Overall, n (\%) & Men, $n(\%)$ & Women, $n(\%)$ \\
\hline Total & 934 & 496 & 438 \\
\hline Mean age, years, (SD) & $52.0(13.9)$ & $51.9(14.0)$ & $52.0(13.8)$ \\
\hline \multicolumn{4}{|l|}{ Age groups, years } \\
\hline $27-34$ & $127(13.6)$ & $71(14.3)$ & $56(12.8)$ \\
\hline $35-44$ & $191(20.4)$ & 97 (19.6) & $94(21.5)$ \\
\hline $45-54$ & $205(21.9)$ & $110(22.2)$ & $95(21.7)$ \\
\hline $55-64$ & $195(20.9)$ & $100(20.2)$ & $95(21.7)$ \\
\hline $65-78$ & $216(23.1)$ & $118(23.8)$ & $98(22.3)$ \\
\hline \multicolumn{4}{|l|}{ Education } \\
\hline Did not complete high school & $598(64.2)$ & $291(58.8)$ & $307(70.2)$ \\
\hline Completed high school & $210(22.5)$ & $118(23.8)$ & $92(21.1)$ \\
\hline Academic education & $124(13.3)$ & $86(17.4)$ & $38(8.7)$ \\
\hline \multicolumn{4}{|l|}{ Number of siblings } \\
\hline $0-3$ & $87(9.3)$ & $45(9.1)$ & $42(9.6)$ \\
\hline $4-7$ & $423(45.3)$ & $222(44.8)$ & $201(45.9)$ \\
\hline$\geq 8$ & $423(45.3)$ & $228(46.1)$ & $195(44.5)$ \\
\hline \multicolumn{4}{|l|}{ Religiosity } \\
\hline Religious & $350(37.6)$ & $161(32.5)$ & $189(43.4)$ \\
\hline Traditional/secular & $580(62.4)$ & $334(67.5)$ & $246(56.6)$ \\
\hline \multicolumn{4}{|l|}{ Marital status* } \\
\hline Married & $764(82.0)$ & $467(94.2)$ & $297(68.1)$ \\
\hline Not married & $168(18.0)$ & $29(5.8)$ & $139(31.9)$ \\
\hline \multicolumn{4}{|l|}{ Smoking } \\
\hline$\geq 1$ cigarettes/day & $241(26.0)$ & $202(40.8)$ & $39(9.0)$ \\
\hline No smoking/other & $687(74.0)$ & $293(59.2)$ & $394(91.0)$ \\
\hline \multicolumn{4}{|l|}{ Obesity } \\
\hline $\mathrm{BMI}<30 \mathrm{~kg} / \mathrm{m}^{2}$ & $522(55.9)$ & $338(68.1)$ & $184(42.0)$ \\
\hline $\mathrm{BMI} \geq 30 \mathrm{~kg} / \mathrm{m}^{2}$ & $412(44.1)$ & $158(31.9)$ & $254(58.0)$ \\
\hline \multicolumn{4}{|l|}{ Sufficient physical activity level } \\
\hline No & $180(19.3)$ & 68 (13.7) & $112(25.6)$ \\
\hline Yes & $754(80.7)$ & $428(86.3)$ & $326(74.4)$ \\
\hline \multicolumn{4}{|l|}{ High physical activity level } \\
\hline No & $265(28.4)$ & $111(22.4)$ & $154(35.2)$ \\
\hline Yes & $669(71.6)$ & $385(77.6)$ & $284(64.8)$ \\
\hline
\end{tabular}

$B M I$ body mass index; $S D$ standard deviation

*Not married included persons who defined themselves as single, divorced, or widowed

was defined as sufficient and as high level. Mean LTL was not found to differ significantly according to the number of siblings $(p=0.2)$ and smoking $(p=0.6)$ (Table 2). Differences in the expected directions in mean LTL, according to age, religiosity, obesity, and high level of physical activity were observed in both men and women. In women, mean LTL differed significantly $(p=0.001)$ according to educational level, being the longest among those with academic education; but such difference was not significant $(p=0.3)$ in men ( $p$ for interaction 0.2). The difference in mean LTL according to marital status was significant in women only ( $p$ for interaction 0.009). The difference in mean LTL according to a modest level of physical activity level was significant among women only ( $p$ for interaction 0.07 ). No significant interactions were found between the other independent variables and sex (see Additional file 1). 
Table 2 Mean leukocyte telomere length $(\mathrm{kb})$ according to sociodemographic and lifestyle factors

\begin{tabular}{|c|c|c|c|c|}
\hline & Total & Mean (SD) & Mean difference $(95 \% \mathrm{Cl})$ & $p$ value \\
\hline Sex & & & & 0.073 \\
\hline Men & 496 & $6.73(0.63)$ & $-0.07(-0.15,0.01)$ & \\
\hline Women & 438 & $6.80(0.59)$ & Reference & \\
\hline Age, years & $\mathrm{df}=4$ & & & $<0.001^{*}$ \\
\hline $27-34$ & 127 & $7.18(0.55)$ & Reference & \\
\hline $35-44$ & 191 & $7.00(0.54)$ & $-0.18(-0.36,-0.01)$ & \\
\hline $45-54$ & 205 & $6.80(0.55)$ & $-0.39(-0.56,-0.21)$ & \\
\hline $55-64$ & 195 & $6.62(0.56)$ & $-0.57(-0.75,-0.39)$ & \\
\hline $65-78$ & 216 & $6.40(0.55)$ & $-0.78(-0.96,-0.61)$ & \\
\hline Education & $\mathrm{df}=2$ & & & $0.007^{* *}$ \\
\hline Did not complete high school or less & 598 & $6.72(0.58)$ & Reference & \\
\hline Completed high school & 210 & $6.83(0.61)$ & $0.11(-0.002,0.23)$ & \\
\hline Academic education & 124 & $6.87(0.71)$ & $0.15(0.01,0.30)$ & \\
\hline Number of siblings & $d f=2$ & & & $0.2^{* * *}$ \\
\hline $0-3$ & 87 & $6.67(0.60)$ & Reference & \\
\hline $4-7$ & 423 & $6.75(0.63)$ & $0.08(-0.09,0.25)$ & \\
\hline$\geq 8$ & 423 & $6.79(0.59)$ & $0.12(-0.05,0.30)$ & \\
\hline Religiosity & & & & $<0.001$ \\
\hline Religious & 350 & $6.67(0.61)$ & $-0.15(-0.23,-0.07)$ & \\
\hline Traditional/secular & 580 & $6.82(0.60)$ & Reference & \\
\hline Marital status ${ }^{* * * *}$ & & & & 0.039 \\
\hline Married & 764 & $6.78(0.62)$ & $0.11(0.01,0.21)$ & \\
\hline Not married & 168 & $6.67(0.56)$ & Reference & \\
\hline Smoking & & & & 0.6 \\
\hline$\geq 1$ cigarettes/day & 241 & $6.78(0.59)$ & $0.02(-0.07,0.11)$ & \\
\hline No smoking/other & 687 & $6.76(0.62)$ & Reference & \\
\hline Obesity & & & & 0.025 \\
\hline $\mathrm{BMI}<30 \mathrm{~kg} / \mathrm{m}^{2}$ & 522 & $6.80(0.62)$ & $0.09(0.01,0.17)$ & \\
\hline $\mathrm{BMI} \geq 30 \mathrm{~kg} / \mathrm{m}^{2}$ & 412 & $6.71(0.60)$ & Reference & \\
\hline \multicolumn{5}{|l|}{ Sufficient physical activity level } \\
\hline No & 180 & $6.60(0.59)$ & $-0.20(-0.29,-0.10)$ & $<0.001$ \\
\hline Yes & 754 & $6.80(0.61)$ & Reference & \\
\hline High physical activity level & & & & $<0.001$ \\
\hline No & 265 & $6.62(0.61)$ & $-0.20(-0.30,-0.10)$ & \\
\hline Yes & 669 & $6.82(0.60)$ & Reference & \\
\hline
\end{tabular}

$B M I$ body mass index; $C l$ confidence intervals; $d f$ degrees of freedom

*ANOVA for the difference between the groups. Bonferroni test $27-34$ vs. $35-44$ ( $p=0.035), 45-54$ vs. $55-64(p=0.013), p<0.01$ for all other pairwise comparisons between the age groups

${ }^{* *}$ ANOVA for the difference between the groups. Bonferroni test: did not complete high school vs. completed high school ( $\left.p=0.055\right)$. Did not complete high school vs. academic degree $(p=0.033)$. Completed high school vs. academic education $(p=1.0)$

${ }^{* * *}$ ANOVA for the difference between the groups. Bonferroni test $p>0.2$ for all pairwise

${ }^{* * * *}$ Not married included persons who reported being single, widowed, or divorced

\section{H. pylori sero-status, atrophic gastritis, and LTL}

H. pylori IgG sero-positivity was found in $780 / 934$ (83.4\%) participants and atrophic gastritis in $81 / 927$ (8.7\%). In persons with a past $H$. pylori infection (lacked
H. pylori IgG serum antibody), atrophic gastritis was found in 37 (4.0\%), atrophic gastritis and H. pylori seropositivity was evident in $44(4.7 \%)$, and $H$. pylori seropositivity without serological evidence of atrophic 
gastritis in 731 (78.9\%), while 115 (12.4\%) tested negative for $H$. pylori and lacked serological evidence for atrophic gastritis

The mean LTL was longer in H. pylori IgG sero-positive persons than in sero-negative ones: $6.78 \mathrm{~kb}$ (SD 0.59 ) vs. $6.65 \mathrm{~kb}$ (SD 0.66), $p=0.016$; the difference was significant only when comparing $H$. pylori sero-positive persons who had CagA IgG serum antibody with those who were sero-negative ( $p=0.018$ by Bonferroni test). Participants who had serological evidence of atrophic gastritis had significantly shorter LTL (6.60 kb [SD 0.65]) than did participants without atrophic gastritis: $6.78 \mathrm{~kb}$ (SD 0.60) $(p=0.011)$. The shortest LTL was found in participants who had past $H$. pylori infection (sero-negative to $H$. pylori IgG antibody) and atrophic gastritis (6.40 kb [SD 0.67]); this compared to persons who were H. pylori sero-negative without atrophic gastritis (6.72 kb [SD 0.63]), those who were $H$. pylori sero-positive without atrophic gastritis (6.79 kb [SD 0.60]), and those who were $H$. pylori sero-positive with atrophic gastritis $(p=0.028, p=0.001$, and $p=0.037$, respectively, by the Bonferroni test) (Table 3).

A multiple linear regression model that included the variable $H$. pylori sero-status/atrophic gastritis and adjusted for age, sex, and religiosity was statistically significant $(F$ statistic $=26.24, p<0.001)$ with an adjusted $R^{2}$ of 0.198 (Table 4). This model showed an inverse dose-response relationship between age and LTL, and significantly shorter LTL in men than in women; beta coefficient $-0.08 \mathrm{~kb}(95 \% \mathrm{CI}-0.15,-0.01), p=0.032$. Compared to participants who were $H$. pylori sero-negative without atrophic gastritis, those with past $H$. pylori infection (sero-negative to $H$. pylori IgG antibody) and with atrophic gastritis had shorter LTL: beta coefficient $-0.21 \mathrm{~kb}(95 \% \mathrm{CI}-0.41,-0.001), p=0.049$; the difference was not significant in $H$. pylori sero-positive persons either with $(p=0.10)$ or without atrophic gastritis $(p=0.3)$. The mean LTL was shorter in religious than traditional/secular participants; beta coefficient $-0.07 \mathrm{~kb}$ (95\% CI $-0.14,0.01$ ), $p=0.078$ (Table 4). The values of variance inflation factor (VIF) in this model ranged from 1 to 2 , suggesting no collinearity.

An additional model that included the variable $H$. pylori/atrophic gastritis sero-status and the following covariates; age, sex, religiosity, education, marital status, number of siblings, smoking, obesity, and physical activity showed similar results with regard to the associations of age, sex, and $H$. pylori/atrophic gastritis serostatus with LTL (see Additional file 2). However, no significant differences in LTL were observed according to obesity $(p=0.6)$, smoking $(p=0.7)$, physical activity $(p=0.5)$, marital status $(p=0.8)$, number of siblings, or education. The adjusted $R^{2}$ of this model was 0.193 , ( $F$ statistic $=13.86, p<0.001)$. The VIF values ranged from

Table 3 Mean leukocyte telomere length (kb) according to H. pylori sero-status and serological evidence of atrophic gastritis

\begin{tabular}{|c|c|c|c|c|}
\hline & Total & Mean (SD) & Mean difference $(95 \% \mathrm{Cl})$ & $p$ value \\
\hline H. pylori lgG sero-status & & & & $0.016^{*}$ \\
\hline H. pylori negative & 154 & $6.65(0.66)$ & Reference & \\
\hline H. pylori positive & 780 & $6.78(0.60)$ & $0.13(0.02,0.24)$ & \\
\hline H. pylori/CagA IgG sero-status & $\mathrm{df}=2$ & & & $0.023^{* *}$ \\
\hline H. pylori negative & 154 & $6.65(0.66)$ & Reference & \\
\hline H. pylori positive CagA negative & 452 & $6.76(0.60)$ & $0.1(-0.01,0.22)$ & $0.19^{* * *}$ \\
\hline H. pylori positive CagA positive & 328 & $6.82(0.59)$ & $0.16(0.05,0.28)$ & $0.018^{* * *}$ \\
\hline Atrophic gastritis $(\mathrm{PGI}<30 \mu \mathrm{g} / \mathrm{L} \text { or } \mathrm{PGI}: \mathrm{PG} \|<3.0)^{\S}$ & & & & $0.011^{*}$ \\
\hline No & 846 & $6.78(0.60)$ & $-0.18(-0.32,-0.04)$ & \\
\hline Yes & 81 & $6.60(0.65)$ & Reference & \\
\hline H. pylori sero-status/atrophic gastritis ${ }^{* * *} \S$ & $d f=3$ & & & $0.002^{* *}$ \\
\hline H. pylori negative no atrophic gastritis & 115 & $6.72(0.63)$ & Reference & \\
\hline H. pylori positive no atrophic gastritis & 731 & $6.79(0.60)$ & $0.07(-0.05,0.18)$ & $1.0^{* * * *}$ \\
\hline H. pylori positive plus atrophic gastritis & 44 & $6.77(0.58)$ & $0.05(-0.16,0.26)$ & $1.0^{* * * *}$ \\
\hline Past H. pylori infection (IgG sero-negatives) plus atrophic gastritis & 37 & $6.40(0.67)$ & $-0.32(-0.55,-0.10)$ & $0.028^{* * * *}$ \\
\hline
\end{tabular}

CagA cytotoxin-associated gene $\mathrm{A}$; $\mathrm{Cl}$ confidence intervals; $d f$ degrees of freedom; IgG immunoglobulin $\mathrm{G}$; $P G$ pepsinogen; $S D$ standard deviation " $p$ value by Student's $t$ test

"ANOVA for the difference between the groups

${ }^{* * * *}$ Bonferroni for multiple comparisons correction compared to H. pylori-negative participants

*****Bonferroni for multiple comparisons correction compared to participants who were $H$. pylori negative and no atrophic gastritis. H. pylori positive no atrophic gastritis vs. past $H$. pylori infection plus atrophic gastritis $(p=0.001)$. H. pylori positive plus atrophic gastritis vs. past $H$. pylori infection (lgG sero-negatives) plus atrophic gastritis $(p=0.037)$

§Information on atrophic gastritis was missing for 7 participants 
Table 4 Multiple linear regression model of adjusted associations of demographic factors, $H$. pylori sero-status, and serological evidence of atrophic gastritis with leukocyte telomere length $(\mathrm{kb})$

\begin{tabular}{ll}
\hline & Beta coefficient $(95 \% \mathrm{Cl})$ \\
\hline Sex & \\
Males & $-0.08(-0.15,-0.01)$ \\
Females & Reference \\
Age, years & \\
$27-34$ & Reference \\
$35-44$ & $-0.19(-0.31,-0.06)$ \\
$45-54$ & $-0.39(-0.51,-0.26)$ \\
$55-64$ & $-0.56(-0.69,-0.44)$ \\
$65-78$ & $-0.76(-0.89,-0.64)$ \\
Religiosity & \\
Religious & $-0.07(-0.14,0.01)$ \\
Traditional/secular & Reference \\
H. pylori sero-status/atrophic gastritis ${ }^{*}$ & \\
H. pylori negative no atrophic gastritis & Reference \\
H. pylori positive no atrophic gastritis & $0.05(-0.06,0.16)$ \\
H. pylori positive plus atrophic gastritis & $0.16(-0.03,0.35)$ \\
Past H. pylori infection (lgG sero-negatives) plus atrophic gastritis & $-0.21(-0.41,-0.001)$ \\
\hline
\end{tabular}

$\mathrm{Cl}$ confidence intervals; lgG immunoglobulin $\mathrm{G}$

*Atrophic gastritis was defined as serum pepsinogen (PG) $I<30 \mu \mathrm{g} / \mathrm{L}$ or PGI:PGII $<3.0$

Model summary: adjusted $R^{2}=0.198$, degrees of freedom $=9,(F$ statistic $=26.24), p<0.001$

Adjusted for the variables in the table

1 to 2 , suggesting no collinearity. No significant interactions were found between $H$. pylori-atrophic gastritis sero-status with sex $(p=0.2)$, age $(p=0.12)$, education $(p=0.11)$, obesity $(p=0.2)$, physical activity $(p=0.12)$, and smoking $(p=0.8)$. Therefore, the interaction terms were excluded from the final model.

\section{Discussion}

We examined associations of $H$. pylori IgG antibody sero-positivity and serological evidence of atrophic gastritis with LTL in a general Arab population sample while assessing the role of sociodemographic and lifestyle factors.

As expected, a significantly shorter LTL was observed in older vs. younger participants and in men vs. women, thus confirming previous findings [5, 7, 8]. Exposure to $H$. pylori infection per se was not associated with shorter LTL. On the contrary, $H$. pylori IgG sero-positivity, especially CagA phenotype, was associated with longer LTL. Serological evidence of atrophic gastritis was associated with shorter LTL, the difference was driven by participants who tested negative to $H$. pylori but had atrophic gastritis. The longer LTL in $H$. pylori sero-positive participants can be explained by the higher prevalence of serological evidence of atrophic gastritis among $H$. pylori seronegative participants $(24.1 \%)$ compared to those who were $H$. pylori seropositive, regardless of whether they were negative or positive for CagA IgG antibody: $5.7 \%$ and $6.0 \%$, respectively, $(p<0.001)$ [42]. Likely, participants who were $H$. pylori sero-negative, but had atrophic gastritis, represent patients with the most severe form of gastric atrophy, which resulted in the loss of $H$. pylori infection [43]. Hence, $H$. pylori might negatively affect LTL only in a subset of infected persons, those with the most severe form of gastric atrophy. These findings confirm our general hypothesis that markers of tissue damage induced by $H$. pylori are related to shorter LTL. The longer duration of $H$. pylori infection observed in older persons is congruent with the acquisition of the infection in early childhood [32, 44], and its persistence [45], unless treated. $H$. pylori infection causes gastritis and typically, with aging, the severity of gastritis increases and atrophic lesions develop in the stomach. The prevalence of atrophic gastritis increases with age [42]. Hence, our findings might also suggest that infection of longer duration might decrease LTL; nonetheless, such interpretation should be made with caution, since information on the time in which the infection was acquired is not available.

On the first impression, our results might seem to contradict our expectations. In fact, our findings fit well with the natural history of $H$. pylori infection, indicating that despite the high prevalence of $H$. pylori infection of $44 \%$ globally [46], generally $H$. pylori does not cause 
disease, and only some infected persons develop peptic disease and gastric cancer (reviewed in [34]). The magnitude of the difference in LTL between persons with past H. pylori infection and atrophic gastritis and those who are H. pylori sero-negative and lacking atrophic gastritis was large (unadjusted mean difference $-0.32 \mathrm{~kb}[95 \% \mathrm{CI}$ $-0.55,-0.10]), p=0.028$. After adjustment for age, sex, and religiosity, the association was slightly attenuated but remained significant (beta coefficient $-0.21 \mathrm{~kb}[95 \%$ CI $-0.41,-0.001]), p=0.049$. A case-control study of gastric cancer in Poland showed an increased risk for gastric cancer in relation to short LTL [47]. The same study showed among the control group, shorter LTL in persons positive than negative for $H$. pylori [47]. A study of non-neoplastic gastric mucosa from 106 cancer-free persons linked epigenetic changes, namely, H. pylori related hypermethylation of the promoter $\mathrm{CpG}$ island, with increased severity of gastritis and the development of atrophy (as measured by the PGI:PGII ratio); while shortened telomere increased the risk for hypermethylation [48]. Collectively, these and our observations shed light on the development of damage to the gastric mucosa in relation to $H$. pylori infection, in which telomere length shortening seems to play an important role. A small cross-sectional study of 163 US adults that examined associations of sero-positivity to four persistent pathogens (CMV, HSV-1, H. pylori, and Chlamydia pneumoniae) with total pathogen burden on LTL, showed reduced LTL in relation to CMV sero-positivity and increased pathogen burden in women $(n=100)$ but not in men $(n=63)$ [30]. LTL did not differ significantly according to $H$. pylori infection and no markers of atrophic gastritis were assessed [30]. Elsewhere, among 400 participants aged $53-76$ years, no significant association was found between CMV IgG sero-prevalence and LTL [49], but telomerase activity was reduced in relation to CMV positivity. Taken together, these and our findings suggest that exposure to persistent infections might play a role in LTL. Our findings suggest that strong specific inflammation of the stomach, as typically induced by $H$. pylori, is negatively associated with LTL. Longitudinal studies are needed to assess the directionality of the association and possible mechanisms between infections and LTL.

Reduced LTL in relation to obesity, and longer LTL in relation to physical activity were observed only in the bivariate analysis of the current study; such associations were not significant in the multivariable models. Smoking was not associated with LTL in our sample. These observations confirm our previous report [15] that was based on a sub-sample $(n=250)$ of the current cohort. Of interest, short LTL was strongly and positively associated with the prevalence of asymptomatic coronary atherosclerosis in that analysis [15].
Unlike previous findings [46], we found a negative association between religiosity and LTL, which was attenuated and became non-statistically significant in the multiple linear regression model that adjusted for age and sex. This suggests that the association between religiosity and LTL might result from confounding. Indeed, more women than men reported being religious (Table 1), and also older than younger participants (see Additional file 3).

Our study has some limitations. Using serum PGs to study atrophic gastritis might have limited sensitivity, which might result in non-differential misclassification of atrophic gastritis. The directionality of the associations of H. pylori sero-status and serological evidence of atrophic gastritis with LTL remain unknown because of the crosssectional study design. Information on previous $H$. pylori eradication therapy was not collected, given the nature of our study, which utilized archived specimens and data that were obtained in a study on cardiovascular risk factors almost one decade ago. Persons with atrophic gastritis might change their dietary habits, yet such information was not available. Therefore, we cannot rule out the possibility of residual confounders.

The response rate to participate in the original study was $77 \%$ among Arabs; we cannot exclude the possibility that the non-responders might have different characteristics than the responders.

Our study has a number of strengths including the large general population sample with the representation of both sexes and various age groups, the attainment of findings of broad generalizability, the comprehensive assessment of demographic and lifestyle factors in addition to $H$. pylori and serum PGs, and the adjustment for confounders.

\section{Conclusions}

In this cross-sectional study, $H$. pylori IgG sero-positivity per se was not related to shorter LTL. However, persons lacking $H$. pylori IgG serum antibody with serological evidence of atrophic gastritis had shorter LTL than did those without atrophic gastritis, independent of other factors that might affect LTL.

\section{Methods}

\section{Study design and population}

We used archived anonymized specimens obtained in the framework of a cross-sectional study conducted during 2004-2008 among Jewish and Arab residents of Jerusalem. Details of the study design have been reported $[15,42$, 50-52]. The current study was limited to the Arab participants for whom LTL measurement was performed.

The sampling frame included all permanent residents of East and West Jerusalem between ages 25-74 years, as recorded in the Israeli National Population Register. 
Random samples were drawn from the register for both population groups, stratified by sex and by 10 -year age groups, 200 names in each stratum, for a total of 2000 names and addresses in each population. These were all invited to participate in the study. Individuals were ineligible if they were unable to provide informed consent, institutionalized, housebound, or had a severe illness; and women, if they were pregnant or gave birth within the 3 months preceding study initiation. The response rate among Arabs was $77 \%(n=970)[15,50]$. We did not perform an a priori power calculation for the current study; we used all the available serum samples, 934/970 representing $96.3 \%$ of the Arab participants in the original study.

\section{Data collection and definitions of the variables}

Data were collected through personal interviews with the participants conducted during 2004-2008. Information was obtained on sex and age in years. Since the data were collected during a 4-year period, we considered age at examination, grouped here as $27-34,35-44,45-54$, 55-64, and 65-78 years).

Self-reported education was classified into three categories: as having an academic degree, completed high school, and did not complete high school [42, 50,52]. Marital status was defined as being married or not married (being single, divorced, or widowed). The variable religiosity was assessed in view of previous reports linking between religiosity and beneficial health outcomes [53-55], and reports on associations between religiosity and LTL [46]. Religiosity was defined based on the participants' reply to a single question: "How do you define yourself?" The possible responses were very religious, religious, traditional, and secular. Since only two participants defined themselves as very religious and only 40 participants defined themselves as secular, the responses were grouped into two categories: religious vs. traditional/secular. Self-reported number of siblings was defined as having $0-3,4-7$, or $\geq 8$ siblings. Smoking was classified as reported smoking of at least one cigarette daily vs. no smoking/other (i.e., smoking less than one cigarette/day). Physical activity was evaluated using the Multi-Ethnic Study of Atherosclerosis questionnaire [50], which assesses all-domains of physical activity including leisure, transport, work, and at home. Physical activity was defined following the World Health Organization (WHO) recommendation for physical activity in adults aged 18-64 years [56]. Participants were classified as sufficiently physically active if they met the WHO recommendation of doing at least $150 \mathrm{~min}$ of at least moderate intensity aerobic physical activity; 75 min of at least vigorous physical activity or an equivalent combination of moderate and vigorous intensity physical activity of at least 600 metabolic equivalents (METs) minutes weekly [56]. Participants were classified as highly active if they met the physical activity level associated with health benefits (i.e., doing at least $300 \mathrm{~min}$ of moderate-intensity aerobic activity throughout the week; or doing at least $150 \mathrm{~min}$ of vigorous-intensity aerobic activity; or an equivalent combination of moderate and vigorous intensity physical activity of at least 1500 METs minutes weekly). Height and weight were measured with light clothing and without shoes. Weight in kilograms was measured to the nearest $100 \mathrm{~g}$ using an analog scale. Standing height was measured to the nearest $0.1 \mathrm{~cm}$. BMI was calculated as weight (in $\mathrm{kg}$ )/height (in meters $[\mathrm{m}])^{2}$. Obesity was defined as $\mathrm{BMI} \geq 30 \mathrm{~kg} / \mathrm{m}^{2}$.

\section{Laboratory methods}

Sera were tested for the presence of specific $H$. pylori IgG antibodies (Enzygnost ${ }^{\circ}$ Anti-Helicobacter pylori II/IgG kit, Siemens Diagnostics Product GmbH, Marburg, Germany). The sensitivity and specificity of the kit are $94-98 \%$. The presence of IgG antibody against recombinant CagA protein was measured in $H$. pylori-positive sera following an in-house ELISA protocol as previously described [42, 52, 57]. H. pylori sero-status was defined as (1) H. pylori negative if participants lacked $H$. pylori IgG antibody; (2) $H$. pylori-positive CagA negative, if they had $H$. pylori IgG antibody but lacked CagA IgG antibody; (3) H. pyloripositive CagA positive if they had both $H$. pylori and CagA IgG antibodies.

The level of serum PGI and PGII was quantified by ELISA (Biohit Inc., Helsinki, Finland) and the ratio of PGI:PGII was calculated. Serological evidence of atrophic gastritis was defined as a serum PGI level of $<30$ $\mu \mathrm{g} / \mathrm{L}$ or PGI:PGII ratio of $<3.0$, as recommended by the manufacturer. Participants were also classified according to $H$. pylori IgG sero-positivity and serological evidence of atrophic gastritis as (1) H. pylori negative, no atrophic gastritis; (2) H. pylori positive, no atrophic gastritis; (3) H. pylori positive plus atrophic gastritis; or (4) H. pylori negative plus atrophic gastritis. Since atrophic gastritis is caused mainly by $H$. pylori infection and severe gastric atrophy results in loss of $H$. pylori infection [43], persons who tested negative to $H$. pylori but had atrophic gastritis were considered as having past $H$. pylori infection. All serological assays were performed in one laboratory at Tel University by an experienced technician who was masked to the LTL results and information on the other independent variables.

The measurement of LTL was performed using southern blot analysis of the terminal restriction fragment length at the laboratory of Professor Abraham Aviv, the Center of Human Development and Aging, Rutgers, The State University of New Jersey, New Jersey Medical 
School, Newark, USA $[15,49]$. LTL (kb) was analyzed as a continuous variable expressed in kilobase pair.

\section{Statistical analysis}

The study sample (overall and by sex) was described using means (and standard deviations (SDs)) for continuous variables, and frequency and percentages for categorical variables. Differences in mean LTL $(\mathrm{kb})$ were examined using the Student's $t$ test for dichotomous variables (i.e., sex, religiosity, marital status, physical activity, obesity, smoking) and one-way analysis of variance (ANOVA) for categorical variables with more than two categories (i.e., age, education, number of siblings, and H. pylori sero-status/atrophic gastritis). The Bonferroni post hoc test was used for pairwise comparisons to adjust for multiple comparisons. The variable LTL followed approximately a normal distribution. The assumptions of equal variance in Student's $t$ test and homogeneity of variance in ANOVA were examined and met. These analyses were performed in stratification by sex, given the documented difference between men and women in LTL [8]. Interactions between sex and the independent variables were assessed as an initial step before running a pooled multivariable model.

Multiple linear regression models were fitted to assess the associations between $H$. pylori sero-status/atrophic gastritis and LTL while adjusting for demographic and lifestyle factors. H. pylori sero-status/atrophic gastritis was enforced into the model as the main independent variable of interest. Other independent variables were selected to be included in the model based on prior knowledge; if the independent variables were associated with LTL (age, sex $[5,7,8]$, religiosity [46], education as a measure of SES [23], smoking [24, 25], obesity [25], and physical activity $[27,28])$, or with $H$. pylori infection (education and number of siblings [58]). Categorical variables were included in the model as dummy variables. Covariates were excluded from the analysis if they were associated with LTL in the model with $p>0.2$, and if they yielded a change of less than $10 \%$ in the point estimate [59] of the association between $H$. pylori serostatus/atrophic gastritis and LTL (suggesting that they were not confounders), or in the adjusted $R^{2}$. This resulted in two multivariable models, for each of them we reported the $p$ value, $F$ statistics, and adjusted $R^{2}$. Interactions between $H$. pylori sero-status/atrophic gastritis and the other independent variables were assessed in the models. For each independent variable, we reported the beta (slope) coefficient (and 95\% CI) that were obtained from these models. The assumptions of the linear regressions were assessed and met in all models. Collinearity between the independent variables was assessed using VIF. Statistical significance was set at $p<0.05$. Data were analyzed using IBM SPSS version 25 (Armonk, NY, USA).

\section{Additional files}

Additional file 1: The results of the sex-stratified analysis of the mean leukocyte telomere length (kb) according to sociodemographic and lifestyle factors. (PDF $192 \mathrm{~kb}$ )

Additional file 2: The results from the additional multiple linear regression model of adjusted associations of demographic and lifestyle factors, $H$. pylori sero-status, and serological evidence of atrophic gastritis with leukocyte telomere length (kb). (PDF 170 kb)

Additional file 3: The self-reported responses regarding religiosity by age groups. (PDF $6 \mathrm{~kb}$ )

\section{Abbreviations \\ ANOVA: One-way analysis of variance; BMI: Body mass index; CagA: Cytotoxin-associated gene A; Cl: Confidence intervals; \\ CMV: Cytomegalovirus; ELISA: Enzyme-linked immunosorbent assay; $H$. pylori: Helicobacter pylori; HSV-1: Herpes simplex virus type 1; kb: kilo base pairs; kg: kilogram; IgG: Immunoglobulin G; LTL: Leukocyte telomere length; m: meter; METs: Metabolic equivalents; PG: Pepsinogen; SD: Standard deviation; VIF: Variance inflation factor; WHO: World Health Organization}

\section{Acknowledgements}

Professor Jeremy D. Kark, our mentor, friend, and colleague, the senior author of the study, passed away. This work is dedicated to his memory. We are very thankful to Professor Guillermo I Perez-Perez and Professor Martin J Blaser from New York University School of Medicine, New York, NY, USA, for providing the recombinant CagA antigen. We thank Ms. Gany Beer-Davidson (Tel Aviv University) for her technical assistance in performing serological assays. We thank Professor Abraham Aviv and his team at The Center of Human Development and Aging, Rutgers, The State University of New Jersey, New Jersey Medical School, Newark, USA, for performing the LTL measurements.

\section{Availability of data and material}

The datasets used and/or analyzed during the current study are available from the corresponding author on reasonable request.

\section{Authors' contributions}

KM, DC, and JDK designed the study and directed its implementation, including quality assurance and control. RS and HN helped supervise the field activities, and the data and sample collection. RS, DM, and KM were responsible for creating the current dataset. KM, DC, DM, and JDK designed the study's analytic strategy. KM analyzed the data and prepared the first draft of the manuscript. All authors contributed to the writing and approved the manuscript.

\section{Funding}

Funding for this study was provided by the USAID MERC Program (Grant \# TA-MOU-01-M21-002) (PI-JDK), by a research grant from DCURE Israel [PIJDK], the Stanley Steyer Institute for Cancer Epidemiology and Research at Tel Aviv University, School of Public Health (PI-DC), and a MAOF scholarship awarded to KM by the Council of High Education.

\section{Ethics approval and consent to participate}

The study was approved by the Institutional Review Boards of Hadassah Medical Center and the St. Joseph Hospital, and by the Ethics Committee of Tel Aviv University. The participants provided written informed consent.

Consent for publication

Not applicable

\section{Competing interests}

The authors declare that they have no competing interests.

\section{Author details}

${ }^{1}$ Department of Epidemiology and Preventive Medicine, School of Public Health, Sackler Faculty of Medicine, Tel Aviv University Ramat Aviv, Ramat Aviv, 6139001 Tel Aviv, Israel. ${ }^{2}$ Hadassah School of Public Health and Community Medicine, Hebrew University, Jerusalem, Israel. ${ }^{3}$ Western Sydney University, Sydney, Australia. ${ }^{4}$ St. Joseph Hospital, East Jerusalem and 
Department of Cardiology, Hadassah-Hebrew University Medical Center, Ein Kerem, Jerusalem, Israel.

\section{Received: 9 April 2019 Accepted: 3 July 2019 Published online: 22 July 2019}

\section{References}

1. Blackburn EH. Telomere states and cell fates. Nature. 2000;408:53-6.

2. Blackburn $\mathrm{E}$, Gall J. A tandemly repeated sequence at the termini of the extrachromosomal ribosomal RNA genes in Tetrahymena. J Mol Biol. 1978; 120:33-53.

3. Blasco MA. Telomere length, stem cells and aging. Nat Chem Biol. 2007;3: 640-9.

4. Aviv A, Shay JW. Reflections on telomere dynamics and ageing-related diseases in humans. Philos Trans R Soc Lond B Biol Sci. 2018;373. https://doi.org/10.1098/rstb.2016.0436.

5. Slagboom PE, Droog S, Boomsma DI. Genetic determination of telomere size in humans: a twin study of three age groups. Am J Hum Genet. 1994; 55:876-82.

6. Broer L, Codd V, Nyholt DR, Deelen J, Mangino M, Willemsen G, et al. Metaanalysis of telomere length in 19,713 subjects reveals high heritability, stronger maternal inheritance and a paternal age effect. Eur J Hum Genet. 2013;21:1163-8

7. Daniali L, Benetos A, Susser E, Kark JD, Labat C, Kimura M, et al. Telomeres shorten at equivalent rates in somatic tissues of adults. Nat Commun. 2013; 4:1597. https://doi.org/10.1038/ncomms2602.

8. Berglund K, Reynolds CA, Ploner A, Gerritsen L, Hovatta I, Pedersen NL, et al. Longitudinal decline of leukocyte telomere length in old age and the association with sex and genetic risk. Aging (Albany NY). 2016;8:1398-415.

9. Hansen MEB, Hunt SC, Stone RC, Horvath K, Herbig U, Ranciaro A, et al. Shorter telomere length in Europeans than in Africans due to polygenetic adaptation. Hum Mol Genet. 2016;25:2324-30.

10. Aviv A. Genetics of leukocyte telomere length and its role in atherosclerosis Mutat Res. 2012;730:68-74

11. Haycock PC, Heydon EE, Kaptoge S, Butterworth AS, Thompson A, Willeit P. Leucocyte telomere length and risk of cardiovascular disease: systematic review and meta-analysis. BMJ. 2014;349:94227.

12. Sanders JL, Newman AB. Telomere length in epidemiology: a biomarker of aging, age-related disease, both, or neither? Epidemiol Rev. 2013;35:112-31.

13. Codd V, Nelson CP, Albrecht E, Mangino M, Deelen J, Buxton JL, et al. Identification of seven loci affecting mean telomere length and their association with disease. Nat Genet. 2013;45:422-7.

14. Benetos A, Toupance S, Gautier S, Labat C, Kimura M, Rossi PM, et al. Short leukocyte telomere length precedes clinical expression of atherosclerosis the blood-and-muscle model. Circ Res. 2018;122:616-23.

15. Kark JD, Nassar H, Shaham D, Sinnreich R, Goldberger N, Aboudi V, et al. Leukocyte telomere length and coronary artery calcification in Palestinians. Atherosclerosis. 2013:229:363-8.

16. Mons U, Muezzinler A, Schottker B, Dieffenbach AK, Butterbach K, Schick M, et al. Leukocyte telomere length and all-cause, cardiovascular disease, and cancer mortality: results from individual-participant-data meta-analysis of 2 large prospective cohort studies. Am J Epidemiol. 2017;185:1317-26.

17. Deelen J, Beekman M, Codd V, Trompet S, Broer L, Hagg S, et al. Leukocyte telomere length associates with prospective mortality independent of immune-related parameters and known genetic markers. Int J Epidemiol. 2014;43:878-86

18. Aviv A, Kark JD, Susser E. Telomeres, atherosclerosis, and human longevity a causal hypothesis. Epidemiology. 2015;26:295-9.

19. Stone RC, Horvath K, Kark JD, Susser E, Tishkoff SA, Aviv A. Telomere length and the cancer-atherosclerosis trade-off. PLOS Genet. 2016;12: e1006144.

20. Wentzensen IM, Mirabello L, Pfeiffer RM, Savage SA. The association of telomere length and cancer: a meta-analysis. Cancer Epidemiol Biomarkers Prev. 2011;20:1238-50.

21. Weischer M, Nordestgaard BG, Cawthon RM, Freiberg JJ, Tybjaerg-Hansen A, Bojesen SE. Short telomere length, cancer survival, and cancer risk in 47102 individuals. J Natl Cancer Inst. 2013;105:459-68.

22. Zhang X, Zhao Q, Zhu W, Liu T, Xie SH, Zhong LX, et al. The association of telomere length in peripheral blood cells with cancer risk: a systematic review and meta-analysis of prospective studies. Cancer Epidemiol Biomarkers Prev. 2017;26:1381-90.
23. Cherkas LF, Aviv A, Valdes AM, Hunkin JL, Gardner JP, Surdulescu GL, et al. The effects of social status on biological aging as measured by whiteblood-cell telomere length. Aging Cell. 2006;5:361-5.

24. Astuti Y, Wardhana A, Watkins J, Wulaningsih W, Network PR. Cigarette smoking and telomere length: A systematic review of 84 studies and metaanalysis. Environ Res. 2017:158:480-9.

25. Valdes AM, Andrew T, Gardner JP, Kimura M, Oelsner E, Cherkas LF, et al. Obesity, cigarette smoking, and telomere length in women. Lancet. 2005;366:662-4.

26. Gielen M, Hageman GJ, Antoniou EE, Nordfjall K, Mangino M, Balasubramanyam $\mathrm{M}$, et al. Body mass index is negatively associated with telomere length: a collaborative cross-sectional meta-analysis of 87 observational studies. Am J Clin Nutr. 2018;108:453-75.

27. Du M, Prescott J, Kraft P, Han J, Giovannucci E, Hankinson SE, et al. Physical activity, sedentary behavior, and leukocyte telomere length in women. Am J Epidemiol. 2012;175:414-22.

28. Cherkas LF, Hunkin JL, Kato BS, Richards JB, Gardner JP, Surdulescu GL, et al. The association between physical activity in leisure time and leukocyte telomere length. Arch Intern Med. 2008;168:154-8.

29. Kark JD, Goldberger N, Kimura M, Sinnreich R, Aviv A. Energy intake and leukocyte telomere length in young adults. Ame J Clin Nutr. 2012;95:479-87.

30. Aiello AE, Jayabalasingham B, Simanek AM, Diez-Roux A, Feinstein L, Meier $\mathrm{HCS}$, et al. The impact of pathogen burden on leukocyte telomere length in the Multi-Ethnic Study of Atherosclerosis. Epidemiol Infect. 2017;145:3076-84.

31. Dowd JB, Bosch JA, Steptoe A, Jayabalasingham B, Lin J, Yolken R, et al. Persistent herpesvirus infections and telomere attrition over 3 years in the Whitehall II Cohort. J Infect Dis. 2017;216:565-72.

32. Muhsen $\mathrm{K}$, Jurban M, Goren S, Cohen D. Incidence, age of acquisition and risk factors of Helicobacter pylori infection among Israeli Arab infants. J Trop Pediatr. 2012;58:208-13.

33. Atherton JC. The pathogenesis of Helicobacter pylori-induced gastroduodenal diseases. Annu Rev Pathol. 2006;1:63-96.

34. Suerbaum S, Michetti P. Helicobacter pylori infection. N Engl J Med. 2002; 347:1175-86.

35. Samloff IM. Cellular localization of group I pepsinogens in human gastric mucosa by immunofluorescence. Gastroenterology. 1971;61:185-8.

36. Samloff IM, Liebman WM. Cellular localization of the group II pepsinogens in human stomach and duodenum by immunofluorescence. Gastroenterology. 1973:65:36-42.

37. Miki K, Urita Y. Using serum pepsinogens wisely in a clinical practice. J Dig Dis. 2007:8:8-14.

38. Nardone G, Rocco A, Staibano S, Mezza E, Autiero G, Compare D, et al. Diagnostic accuracy of the serum profile of gastric mucosa in relation to histological and morphometric diagnosis of atrophy. Aliment Pharmacol Ther. 2005;22:1139-46.

39. Kekki M, Samloff IM, Varis K, Ihamaki T. Serum pepsinogen I and serum gastrin in the screening of severe atrophic corpus gastritis. Scand J Gastroenterol Suppl. 1991;186:109-16.

40. Zagari RM, Rabitti S, Greenwood DC, Eusebi LH, Vestito A, Bazzoli F. Systematic review with meta-analysis: diagnostic performance of the combination of pepsinogen, gastrin-17 and anti-Helicobacter pylori antibodies serum assays for the diagnosis of atrophic gastritis. Aliment Pharmacol Ther. 2017;46:657-67.

41. Sipponen P, Graham DY. Importance of atrophic gastritis in diagnostics and prevention of gastric cancer: application of plasma biomarkers. Scand J Gastroenterol. 2007:42:2-10.

42. Muhsen K, Sinnreich R, Merom D, Beer-Davidson G, Nassar H, Cohen D, et al. Prevalence and determinants of serological evidence of atrophic gastritis among Arab and Jewish residents of Jerusalem: a cross-sectional study. BMJ Open. 2019;9:e024689.

43. Karnes WE Jr, Samloff IM, Siurala M, Kekki M, Sipponen P, Kim SW, et al. Positive serum antibody and negative tissue staining for Helicobacter pylori in subjects with atrophic body gastritis. Gastroenterology. 1991;101:167-74.

44. Muhsen K, Athamna A, Athamna M, Spungin-Bialik A, Cohen D. Prevalence and risk factors of Helicobacter pylori infection among healthy 3- to 5-yearold Israeli Arab children. Epidemiol Infect. 2006;134:990-6.

45. Muhsen K, Athamna A, Bialik A, Alpert G, Cohen D. Presence of Helicobacter pylori in a sibling is associated with a long-term increased risk of $\mathrm{H}$. pylori infection in Israeli Arab children. Helicobacter. 2010;15:108-13.

46. Hill TD, Ellison CG, Burdette AM, Taylor J, Friedman KL. Dimensions of religious involvement and leukocyte telomere length. Soc Sci Med. 2016; 163:168-75. 
47. Hou LF, Savage SA, Blaser MJ, Perez-Perez G, Hoxha M, Dioni L, et al. Cancer Epidemiol Biomarkers Prev. 2009;18:3103-9.

48. Tahara T, Shibata T, Okubo M, Kawamura T, Horiguchi N, Ishizuka T, et al. Demonstration of potential link between Helicobacter pylori related promoter $\mathrm{CpG}$ island methylation and telomere shortening in human gastric mucosa. Oncotarget. 2016;7:43989-96.

49. Kimura M, Stone RC, Hunt SC, Skurnick J, Lu X, Cao X, et al. Measurement of telomere length by the Southern blot analysis of terminal restriction fragment lengths. Nat Protoc. 2010;5:1596-607.

50. Merom D, Sinnreich R, Aboudi V, Kark JD, Nassar H. Lifestyle physical activity among urban Palestinians and Israelis: a cross-sectional comparison in the Palestinian-Israeli Jerusalem risk factor study. BMC Public Health. 2012;12:90. https://doi.org/10.1186/1471-2458-12-90.

51. Weiss R, Nassar H, Sinnreich R, Abu-Ahmad W, Otvos J, Kark JD. Palestinian Arab ethnicity is associated with an adverse metabolic phenotype. Clin Chim Acta. 2017;475:56-63.

52. Muhsen K, Sinnreich R, Beer-Davidson G, Nassar H, Cohen D, Kark JD. Seroprevalence of Helicobacter pylori CagA immunoglobulin G antibody, serum pepsinogens and haemoglobin levels in adults. Sci Rep. 2018;8:17616.

53. Burazeri G, Goda A, Kark JD. Religious observance and acute coronary syndrome in predominantly Muslim Albania: a population-based casecontrol study in Tirana. Ann Epidemiol. 2008;18:937-45.

54. Kraut A, Melamed S, Gofer D, Froom P. Association of self-reported religiosity and mortality in industrial employees: the CORDIS study. Soc Sc Med. 2004;58:595-602.

55. Jaffe $\mathrm{DH}$, Eisenbach Z, Neumark YD, Manor O. Does living in a religiously affiliated neighborhood lower mortality? Ann Epidemiol. 2005;15:804-10.

56. Physical activity and adults: recommended levels of physical activity for adults aged 18 - 64 years [http://www.who.int/dietphysicalactivity/ factsheet_adults/en/]. Accessed Sept 2018.

57. Blaser MJ, Perez-Perez Gl, Kleanthous H, Cover TL, Peek RM, Chyou PH, et al. Infection with Helicobacter pylori strains possessing cagA is associated with an increased risk of developing adenocarcinoma of the stomach. Cancer Res. 1995;55:2111-5

58. Rothenbacher D, Bode G, Winz T, Berg G, Adler G, Brenner H. Helicobacter pylori in out-patients of a general practitioner: prevalence and determinants of current infection. Epidemiol Infect. 1997:119:151-7.

59. Greenland S. Modeling and variable selection in epidemiologic analysis. Am J Public Health. 1989:79:340-9.

\section{Publisher's Note}

Springer Nature remains neutral with regard to jurisdictional claims in published maps and institutional affiliations.

Ready to submit your research? Choose BMC and benefit from:

- fast, convenient online submission

- thorough peer review by experienced researchers in your field

- rapid publication on acceptance

- support for research data, including large and complex data types

- gold Open Access which fosters wider collaboration and increased citations

- maximum visibility for your research: over $100 \mathrm{M}$ website views per year

At BMC, research is always in progress.

Learn more biomedcentral.com/submissions 